\title{
Study on Translation Strategy of "Unconscious" Theoretical Documents from the Perspective of Pure Language Theory
}

\author{
Junming Xiao
}

Qiqihar Medical University, Qiqihar, Heilongjiang,161006

Keywords: Unconscious Theory, Pure Language Theory, Translation Strategy

\begin{abstract}
The theory of unconsciousness is not only a concept of psychology, but also a concept that is common to other disciplines. The importance of translation is evident. The vocabulary of texts can be classified into technical terms, semi-technical terms and general terms. This paper introduces the literature translation strategies.
\end{abstract}

\section{Introduction}

The prevalence of unconsciousness in the West can be traced back to the middle of the 19th century. Many thinkers and psychologists mentioned the theory of unconsciousness. Freud gave the academic status of unconsciousness theory. He thought that the psychological process is mainly composed of unconsciousness in operation, it is more important than awareness and is "real spiritual reality." The theory of unconsciousness is an important part of the theory of psychoanalysis. It expands the research field of psychology and inspires people to explore the human psychological phenomenon from multiple perspectives. Nowadays, the unconscious theory has been psychopathology, philosophy, psychology, psychiatry and history Learning and other disciplines share the concept. Accordingly, it is more necessary to pay attention to the accuracy and normativity of the translation, analyze the characteristics of the vocabulary and seek effective translation strategies.

\section{Analysis of Vocabulary in "Unconsciousness" Theory}

The translated texts involve psychology and philosophical research. There are a large number of professional terms involved in the text. According to the degree of professional vocabulary, the texts can be divided into the following three categories: (1) Specialized vocabulary: a specialized vocabulary or term used only in a particular profession or discipline, Meaning, semantic boundaries and the scope of application is very clear. There are many more such words in The Unconscious, such as idealism, psychoanalysis, mental confusion, epistemology, exnihilo, antiabstractionism, etc. (2) Semi-professional vocabulary: Derived from common vocabulary, these words have their own general meaning, but have different meanings in different disciplines and professions. For example, the term "support" usually includes "support, Support, support, etc. "in The Unconscious." The word "necessity" is usually the meaning of "necessity, necessities," and is translated as "necessity." "Idea" is usually the "idea" "Meaning, in the Unconscious" idea "means, and so on. (3) Common Vocabulary: In a specific context, common vocabularies are translated into professional terms after obtaining new vocabularies, for example: beg the question (mindlessness); sense - awareness transference (empathy); mental state (mental state) and so on.

\section{The Application of Conscious and Unconscious Education in English Translation Teaching}

Conscious teaching refers to the preparation of students' specialized and concentrated education in the form of pre-class preparation through teacher lectures, expert lectures, student speeches or participation in discussions. The unconscious teaching refers to the educators use the unconscious mind, the education content in a certain living environment, and guide the educators to feel and experience, so that they are subtle in education, so as to achieve a teaching mode of educational 
purposes. This article from the specific teaching of English translation, talk about the author in the specific operation of conscious and unconscious teaching application.

First, teachers must understand the status of the students, implement the "translation in practice" consciousness. Under normal circumstances, students with this awareness, that is, "conscious" students, often take the form of earnestly and skillfully taking notes, practicing constant refinements, using practical translation theory knowledge, For all kinds of translation, but not because of the difficult negative psychology. They usually have a sense of accomplishment and pleasure when they learn to use a skill, and they will further combine theory with practice. For those who do not have this awareness, often manifested as: do not take notes, practice discarded or dunce words. For such students, teachers should urge them to take notes, tips on what methods or skills to translate. Under normal circumstances, for most students, do not like to rigidly explain the theory of the rules and regulations, which requires teachers to be conscious before the class to make full preparation, class first let students practice practice to remind them to pay attention to some Words and structure of translation, let them do it yourself, the discussion reached a variety of translations, and then comment on the explanation, so that students learn from each other ways and means of learning, thinking and practice. Finally, teachers will be these versions according to the intention of a good design, into the specific theory to explain, so that students unknowingly mastered the application of theory and skills. Second, the team should promote cooperation and team learning in the process of translation practice. Each individual has his or her own opinion, correctness or wrongness in the learning process. Through group discussion, several individuals get together and share knowledge and learn from each other. Students in the cooperation process, consciously use language to express their views and opinions, so that others share knowledge. Moreover, the students also provided methods and knowledge to others in unconsciousness such as the way of thinking, the way of thinking, the point of thinking. In the process, teachers help participants to acquire faster skills to learn from others. Especially in the process of discussion, when all kinds of views are in fierce conflicts, teachers should be able to point out the characteristics and advantages and disadvantages of various points of view for the team, so that tangible knowledge can be imparted to students more effectively and effectively so that students can learn from experience Learn, learn from their experiences with other classmates, and learn from criticisms and suggestions received by individuals. Thirdly, teachers' experience, knowledge and teaching methods and means are different in teaching of translation. In addition, teaching is often limited and influenced by certain conditions, such as learning environment, teaching content, teaching forms, teaching art, etc. Always affect the teaching effectiveness. If teachers want to be psychologically attractive to students in class and make students willing to be taught and improve their learning interest and ability, they must be well prepared before class, in class and after class. For example, before class, Students' situations include the activity level, temperament and hobbies of students. In class, students are assigned roles according to different students. Different types of students are divided into different groups according to the situation of each group. Under normal circumstances, students are willing to do it yourself, willing to accept the specific tasks assigned by the teacher, can actively cooperate with each other, and consciously enter the learning situation. In this way, students can develop the ability to summarize the knowledge, but also to develop their ability to dialectical thinking.

\section{Vocabulary Translation Techniques}

The vocabulary in this translation study mainly exists in the field of psychology and philosophy, and some specialized words are the regenerative words formed by the author adding the prefix of the negative prefix, which increases the difficulty of translation for the translator. If the translator can not correctly understand and translate such Buzzwords not only affect the quality of the translation, but also have unpredictable effects on the reader of the translation. Therefore, the translator must establish a glossary of terms for the text before translating. According to the theory of pure language translation, "pure language" between the source language and the translated language is sought, and the same thing in the text is conveyed to different readers in different languages, but the same language effect is produced, and the best translation effect is achieved. 
Translation methods used are literal translation and free translation.

Some specialized words in the text translation can be translated one by one according to their meaning. Therefore, the translator often uses the literal translation method to find the Chinese words that exactly correspond to the meaning of the source text. Although the same thing has different forms in different languages, In the same way, translators should pursue the "pure language" of such words in their translation. For example: epistemology, unconscious, idealism, psychoanalysis, and more. Literal translation can also be applied directly to English terminology that conforms to the Chinese grammatical structure, and translations of terminological terms one by one are often translated from left to right, such as physical world, mental con-fusion, Psychic defense, the dynamic un-conscious, and the like. However, there are grammatical differences between the source language and the target language, and some terms need to be appropriately adjusted, such as: the nature of the unconscious, phenomena transference. Example 1: Original, whatever motivation there may be for phenomenal-ism with regard to the physical world carries over very poorly to themental. First, phenomenology is related to the physical world, so any motivation in phenomenological theory can hardly be attributed to mental categories.

The free translation of a word mainly considers the meaning of a word in the source language text or deduces it according to the specific context of the word or expands the meaning of the word on the basis of the general meaning of the translated word. Without an exactly equivalent target word, Then the translated words should be explained. The author of the text uses more pre-lexical prefixes to derive new words. Such lexicons find it difficult to find the exact meanings in the dictionary or match the original lexical meaning. Most of these derived lexicons are mainly composed of negative prefixes The new meaning, the translation of the need to find the corresponding root of the Chinese meaning of the word, and contextual understanding of the context to find the true meaning of such words, the meaning of negative prefix translation. For example: Antiabstractionism: The objection is that the notion of unconscious mentality involves a conceptual extrapolation from con-scious mentality of a kind that is objectionable, as an illegitimate "abstraction" from known reality. Anti-abstractionism: Anti-abstraction refers to the concept of an unconscious mental state covering conceptual inferences about dissenting state of consciousness, just as in the notion of "abstraction" known to be unreasonable. Analysis: antiabstractionsm prefix is anti -, which means objection in Oxford Advanced Learner's Dichotomy dictionary; anti (which can be combined with nouns and adjectives), according to the collected information, the translator discovers similar expressions, such as anti-intellect Anti-intel-intellectualism and antirealism, and so on, to preliminarily determine that antiabstractionsm means "anti"; then, combined with the context, the text also explains the word, based on the text colon After the interpretative content of the word free translation, drawn anti abstractionsm translated into Chinese as "anti-abstractionism." Example 3: Original text: James considers that we might be inclined to introduce unconscious states to account for habitualaction, for the non reflective exercise of complex competences, andforthecapacitytomakeassociativeconnectionsbetweenidentiallyreflectively. James argues that we tend to use unconscious mind states to explain non-reflexive movements of habitual movement, complex abilities, and the ability to associate thoughts non-reflectively. In addition, some terms in philosophical texts come from other languages such as Latin. They contain special meanings in the philosophical texts of English. The authors use such words to express their academic views concisely, but such words become obstacles in the process of Chinese translation. This situation requires the translator to have a certain background of professional knowledge, and the translator should first define the English paraphrase of the foreign words in the text and make a free translation based on the viewpoint to be elaborated in the original text.

\section{Conclusion}

The common professional vocabulary in the text will not form a substantive translation obstacle, but the foreign language in the professional expression needs the translator to carefully study and understand the specific meaning of the vocabulary in the context. According to the translator's philosophical background knowledge, Conversion, to maximize the fidelity of academic 
information.

\section{Acknowledgement}

Fund Project: "Unconsciousness" theoretical literature translation to promote the academic concept of mental health specialist Faculty facilitation study

Project No.: QYSKL2015-06

\section{References}

[1] Zhang Xiaoqian. English Translation Teaching and Cultural Accomplishment - A Comparison of Chinese and Western Tea Culture [J]. Fujian Tea. 2017 (10)

[2] Jia Yuhui. Analysis of English translation of college English teaching ability of students to enhance [J]. Talent. 2017 (18)

[3] Wu Xiaowen. College English translation teaching reform [J]. Contemporary Educational Practice and Teaching Research. 2017 (08)

[4] Wu Kejia. The application of block-based teaching model in English translation teaching [J]. Journal of Hunan Tax College. 2017 (03)

[5] Ma Jingxin. Based on constructivist English translation teaching reform explore [J]. West Quality Education in Western 2017 (15)

[6] Li Hui. The use of ice and corpus in medical English translation teaching - Taking synonym discrimination and terminology selection as an example [J]. Education and Teaching Forum. 2017 (37) 